\title{
(6) OPEN ACCESS \\ Diagnosing the severity of dry eye: a clear and practical algorithm
}

\author{
Christophe Baudouin, ${ }^{1,2,3}$ Pasquale Aragona, ${ }^{4}$ Gysbert Van Setten, ${ }^{5}$ \\ Maurizio Rolando, ${ }^{6}$ Murat Irkeç, José Benítez del Castillo, ${ }^{8}$ Gerd Geerling, ${ }^{9}$ \\ Marc Labetoulle, ${ }^{10}$ Stefano Bonini, ${ }^{11}$ ODISSEY European Consensus Group members
}

\begin{abstract}
${ }^{1}$ Quinze-Vingts National Ophthalmology Hospital, Paris, France

${ }^{2}$ UPMC University, Paris 6 Vision Institute, INSERM UMRS968, CNRS UMR7210, Paris, France

${ }^{3}$ University of Versailles SaintQuentin en Yvelines, Versailles, France

${ }^{4}$ University of Messina,

Messina, Italy

${ }^{5}$ St. Eriks Eye Hospital,

Stockholm, Sweden

${ }^{6}$ University of Genoa, Genoa, Italy

${ }^{7}$ Hacettepe University School of Medicine, Ankara, Turkey

${ }^{8}$ Hospital Clínico San Carlos,

Madrid, Spain

${ }^{9}$ University of Düsseldorf, Düsseldorf \& University of

Würzburg, Düsseldorf, Germany

${ }^{10}$ South Paris University, Kremlin-Bicêtre, Paris, France

${ }^{11}$ University Campus Bio-

Medico, Rome, Italy
\end{abstract}

Correspondence to Professor Christophe Baudouin, Quinze-Vingts National Ophthalmology Hospital 28 rue de Charenton, Paris 75012, France; Baudouin@quinze-vingts.fr

Received 13 November 2013 Revised 17 January 2014 Accepted 17 February 2014 Published Online First 13 March 2014
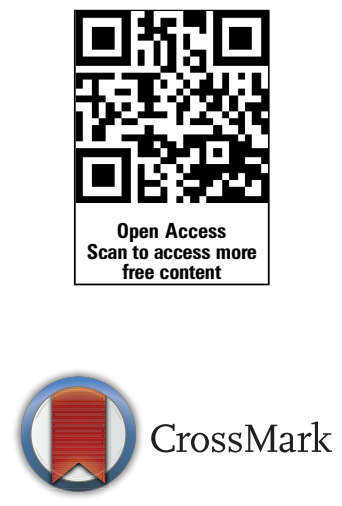

To cite: Baudouin $C$ Aragona P, Van Setten $G$, et al. Br J Ophthalmol 2014;98:1168-1176.

\section{ABSTRACT}

Dry eye disease (DED) is a distressing ocular condition. Due to its multifactorial nature, clinical and biological signs of DED can be inconsistent and sometimes discordant with symptomatology. Consequently, no gold-standard model for determining DED severity exists. This can impact treatment decisions and complicate evaluation of disease progression, particularly within the stringent context of clinical trials. The multinational ODISSEY European Consensus Group is comprised of ophthalmologists who contend with ocular surface disease issues on a daily basis. This group convened to establish a clear and practical algorithm for evaluation and diagnosis of severe DED. Using a consensus-based approach, they assessed 14 commonly used DED severity criteria. The panel agreed that following confirmed DED diagnosis, just two criteria, symptom-based assessment and corneal fluorescein staining were sufficient to diagnose the presence of severe DED in the majority of patients. In the event of discordance between signs and symptoms, further evaluation using additional determinant criteria was recommended. This report presents the ODISSEY European Consensus Group recommended algorithm for DED evaluation, which facilitates diagnosis of severe disease even in the event of discordance between signs and symptoms. It is intended that this algorithm will be useful in a clinical and developmental setting.

\section{INTRODUCTION}

Dry eye disease (DED) is a common ocular condition which significantly reduces quality of life, and affects $6-34 \%$ of the global adult population. ${ }^{12}$

Pathological dry eye was first described as keratoconjunctivitis sicca (KCS) over 70 years ago, ${ }^{3-5}$ and although DED and KCS are not strictly synonymous (as DED can present without keratitis ${ }^{6}$ ), this report will follow accepted dogma by assuming that the terms DED and KCS are interchangeable, and adopt the following 2007 International Dry Eye Workshop (DEWS) definition:

Dry eye is a multifactorial disease of the tears and ocular surface that results in symptoms of discomfort, visual disturbance, and tear film instability with potential damage to the ocular surface. It is accompanied by increased osmolarity of the tear film and inflammation of the ocular surface. ${ }^{5}$

There are relatively few effective treatments for DED, especially for severe disease. ${ }^{7}$ Clinical development of new DED treatments is slow, partly because of problematic diagnosis and classification. ${ }^{8}$ DED pathogenesis and presentation is multifarious, and symptomatology and signs of DED can be inconsistent. Many disease severity criteria currently used by ophthalmologists are confounded by complex disease subtypes and a lack of standardisation, and the selection of single criteria for assessment of disease severity is therefore fraught with difficulties. ${ }^{9-11}$ This lack of dependable diagnostic criteria for disease progression and therapeutic response can undermine clinical trial success and complicate clinical decision making. ${ }^{8} 11-13$

\section{The vicious circle of disease progression}

Numerous extrinsic and intrinsic factors can trigger DED by negatively impacting tear film stability and tear hyperosmolarity; activating osmotic/mechanical stress mechanisms. ${ }^{14-17}$ This leads to apoptosis, ocular cell damage, and release of inflammatory mediators, increasing ocular surface stress and leading to potential epithelial damage. ${ }^{51819}$ Chronic inflammatory response is now thought to be one of the most important mechanisms in DED pathogenesis. ${ }^{20}$

In the early stages of mild or moderate DED, the eye can adapt and introduce compensatory mechanisms, and the condition will respond to treatment. ${ }^{21}$ However, if initial damage is prolonged or too severe, goblet cell repair mechanisms can falter and mucin production becomes dysregulated. Altered mucin production can reduce tear-film stability, and a deadly feedback loop of escalating inflammation can manifest. This cycle has been termed the 'vicious circle' (figure $1^{22}$ ). No matter how the cycle starts, once it establishes it can lead to severe treatmentrefractory disease and permanent damage if no corrective treatment is given. ${ }^{22} 23$

\section{Discordance between DED signs and symptoms}

Many DED pathophysiological mechanisms stimulate sensory neurons of the cornea, and DED has sometimes been described as a 'symptomatic disease'.24-26 For the majority of DED patients, there is some relation between symptoms and clinical signs. However, it is also well established that perceived symptom severity may not equate to clinical signs of disease, and there exists a significant proportion of patients who have seemingly conflicting signs and symptoms. ${ }^{1025} 27$ Indeed, one study showed that up to $40 \%$ of patients had symptom and clinical sign discordance. ${ }^{12}$ Another study showed meibomian gland disease was more commonly asymptomatic than symptomatic $(21.9 \%$ vs $8.6 \%$, respectively), and symptom presentation did not correlate with severity of ocular surface damage. ${ }^{28}$ Physiological mechanisms can partly account for these discrepancies. ${ }^{22} 29$ 
Figure 1 The vicious circle of inflammatory dry eye disease. Editions Elsevier Masson. Reproduced with permission from Baudouin C. The vicious circle in dry eye syndrome: a mechanistic approach. J Fr Ophtalmol 2007;3:239-246 (figure 4).

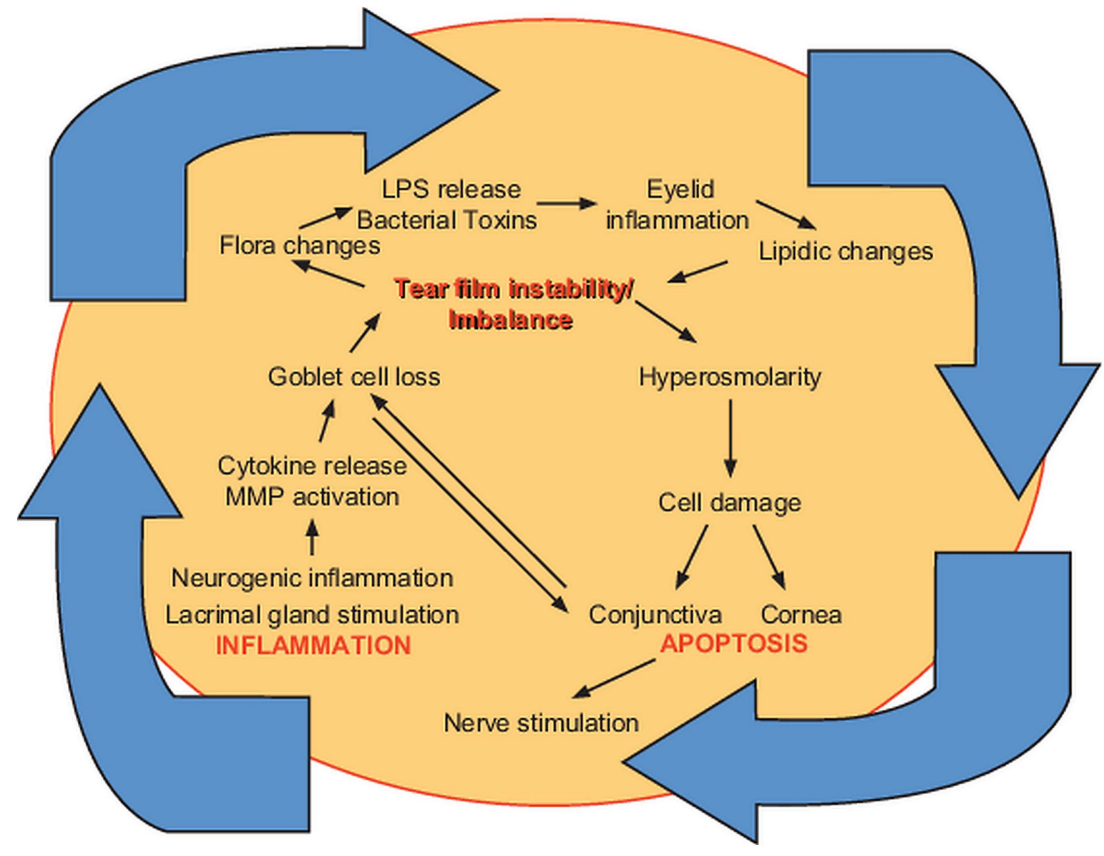

In early or mild DED, the presence of hyperalgesia can cause significant ocular discomfort without any signs of tissue damage. ${ }^{24} 26$ Yet in more severe or chronic disease, decreased corneal sensation due to compensatory reflex mechanisms can actually reduce discomfort. ${ }^{8}{ }^{30}$ Corneal sensory neurons can sometimes also be permanently damaged by very severe $\mathrm{DED}$, or by the underlying causal disease leading to DED. ${ }^{31} 32$

In addition to the physiological explanation of discordance, the variable specificity, sensitivity and reproducibility of some clinical/biological marker evaluations can introduce the potential for false results. This may also confound severity assessments and contribute to supposed symptom and sign discordance. ${ }^{11}$ In one study, over $60 \%$ of patients remained poorly classified in terms of disease severity even when a combination of clinical markers was applied. ${ }^{9}$

This apparent paradoxical disconnect between signs, symptoms and severity makes symptomatology alone a relatively poor indicator of severity in some patients, and also a confounding variable in clinical trials. ${ }^{12} 29$

\section{Evaluation of DED severity}

There is still no gold-standard model for determining DED severity. $^{9-11}$ In 2006, a Delphi panel of DED specialists agreed that disease severity is one of the most relevant factors when considering therapeutic options for DED. ${ }^{33}$ They subsequently recommended a DED severity grading which was later adopted by the DEWS. ${ }^{5}$ Severity was categorised into four levels, based on increasing frequency and intensity of various signs and symptoms. Patient-reported symptoms included requirement of tear substitute, ocular discomfort and visual disturbance. Clinical signs included conjunctival injection, conjunctival and corneal staining, corneal/tear signs (ie, filamentary keratitis), lid/meibomian glands, tear break-up time (TBUT; fluorescein based), and Schirmer score. This system is advantageous in terms of simplicity and practicality, but requires severe symptoms AND severe signs before severe disease is diagnosed. Therefore, this algorithm may not be suitable for patients whose signs and symptoms do not concur. The aim of this consensus group was to build on the DEWS methodology and optimise tailored diagnostic methods specifically for severe DED.

\section{THE ODISSEY EUROPEAN CONSENSUS GROUP}

An algorithm that identifies the criteria most relevant to the patient will allow for targeted evaluation of the ocular surface and facilitate assessment of disease severity. This 'bespoke' approach to evaluation of severe DED will help to define the most appropriate treatment in the clinical setting, and will also allow for better designed clinical trials. ${ }^{9}$ With this aim in mind, the ODISSEY European Consensus Group, comprising 10 ophthalmologists (including one American) who all contend with ocular surface disease issues on a daily basis, was formed.

Members were first asked to complete an electronic questionnaire aimed at finding out which clinical and biological criteria they thought were important for diagnosing severe DED. They then attended a day-long meeting in September 2012. The aim of this meeting was to review clinical and scientific challenges in diagnosis and management of severe DED, and to achieve consensus agreement on a simplified approach to severe DED evaluation. A total of 14 criteria for DED severity were discussed. Advantages and issues were addressed, and also their specificity and sensitivity for diagnosing severe DED. Appropriate scales of assessment and reference values for each criterion were also suggested, based on clinical judgement and the literature.

The following markers and evaluations were discussed:

- Corneal fluorescein staining (CFS)

- Tear hyperosmolarity

- Schirmer test

- Impression cytology

- Filamentary keratitis

- Conjunctival staining

- Impaired visual function

- Meibomian gland disease or eyelid inflammation

- Blepharospasm

- TBUT

- Aberrometry

- In vivo corneal confocal microscopy 
- Inflammatory biomarkers (ie, HLA-DR (human leukocyte antigen-DR), MMP9 (matrix metalloproteinase 9), cytokines, tear proteomics)

- Refractory to standard disease treatments

\section{A SIMPLIFIED AND PRACTICAL APPROACH TO EVALUATING DED SEVERITY}

Following extensive review of current knowledge, questionnaire results analysis and discussion, the ODISSEY European Consensus Group defined a two-step scoring algorithm for diagnosing severe DED (figure 2). The algorithm addresses the challenge of symptom and sign discordance in some cases of severe DED, and describes specific criteria relevant to evaluating DED severity in three different patient scenarios.

\section{Step 1: fundamentals of severe DED diagnosis}

The first step of the scoring algorithm evaluates the minimum number of fundamental criteria required for severe DED diagnosis. It was recommended by the panel that just two criteria, a symptomatic assessment and an evaluation of ocular surface damage by CFS would be sufficient to adequately evaluate severity for the majority of patients. These two criteria are discussed below.

Symptomatology and CFS as the primary assessment criteria DED symptoms of ocular discomfort and visual disturbance can seriously impact patients' quality of life. ${ }^{25}$ The Food and Drug Administration (FDA) has emphasised the importance of patientreported outcomes as clinical endpoints in ophthalmological

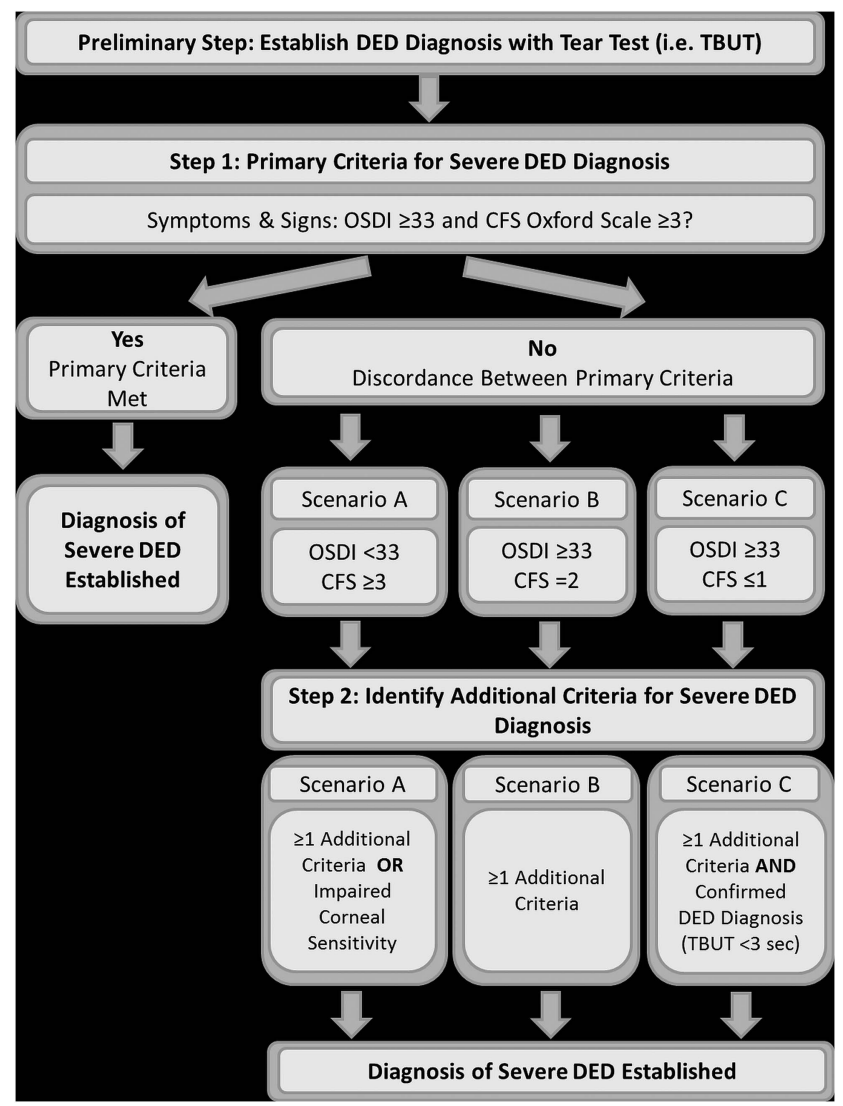

Figure 2 Consensus derived scoring algorithm for severe DED diagnosis. DED, dry eye disease, TBUT, tear break-up time, sec, second, CFS, corneal fluorescein staining, OSDI, Ocular Surface Disease Index. trials, ${ }^{34}$ and a number of validated questionnaires have been developed to assess symptoms of dry eye. ${ }^{35-38}$ These tools are generally economically viable, correlate well with quality of life, have good sensitivity for DED diagnosis, and can be easily quantified. However, the panel also acknowledged that symptom assessments may not be easily reproducible, are not necessarily specific for DED, and their use may carry a risk of overtreatment. The Ocular Surface Disease Index (OSDI) is one of the most widely used questionnaires. The OSDI and similar tools have been shown to correlate moderately well with disease severity, and to a similar degree as corneal staining (eg, $\mathrm{r}^{2}=0.41$ vs $\mathrm{r}^{2}=0.43$, respectively). ${ }^{9}$ However, other studies show poor correlation. ${ }^{9} 27353839$ Nevertheless, it is generally accepted that an OSDI score of around 30 or over is necessary for diagnosis of severe DED. ${ }^{40}$

CFS is a widely used diagnostic test useful for assessing the health of the cornea. CFS was considered by the panel to be the single most appropriate test of DED signs. It is easy to perform, inexpensive, reproducible and can correlate with visual acuity and disease severity. ${ }^{8} 9$ CFS requires a standardised assessment procedure; also no method of objective quantification is available. However, a score $\geq 3$ on the Oxford Scheme generally indicates severe DED. ${ }^{14}$ It must also be remembered that CFS will stain all corneal damage non-specifically, irrespective of cause (eg, refractive laser surgery and drug toxicity). ${ }^{41}$ Ambiguous, asymmetrical and artefact staining patterns can also be an issue, as can sensitivity in mild disease (similar to all known markers of DED). ${ }^{8} 1329$

Following discussion, ODISSEY members decided that combined use of CFS and symptom-based assessment can provide a reliable 'frontline' diagnostic approach for evaluation of DED severity, and that an OSDI score $\geq 33$ and CFS score $\geq 3$ on the Oxford scheme is enough to clearly establish a diagnosis of severe DED in those patients whose signs and symptoms of disease associate well. Thus, it was recommended that these criteria should be adopted for Step 1 of the diagnostic algorithm (figure 2). However, in cases of discordance, it was recommended that further additional evaluations are needed in order to improve diagnostic specificity.

\section{Step 2: additional criteria for severe DED diagnosis}

The panel agreed that when there is discordance between DED signs and symptoms, that is, when OSDI and CFS severity scorings are not in agreement, additional criteria are necessary to establish severe DED. Three possible outcomes after CFS and OSDI assessment in Step 1 were defined:

- Scenario A: if OSDI $<33$ and CFS $\geq 3$. Symptomatology is not indicative of severe disease despite severe ocular surface damage.

- Scenario B: if OSDI $\geq 33$ and $\mathrm{CFS}=2$. Symptomatology is severe, but ocular surface damage is borderline or inconclusive.

- Scenario C: if OSDI $\geq 33$ and $\mathrm{CFS} \leq 1$. Symptomatology is severe, but ocular surface damage is not particularly evident.

The disposition of each patient in Step 2 (ie, Scenario A, B, or C) determines the additional criteria recommended to further evaluate DED severity.

The clinical and biological signs were divided by the panel into two groups. Each criterion was labelled as either being 'determinant' or 'contributory' to diagnosis of severe DED. A summary of the issues discussed by the panel with regards to each criterion is outlined in table 1 for criteria defined as determinant, and table 2 for criteria defined as contributory. 


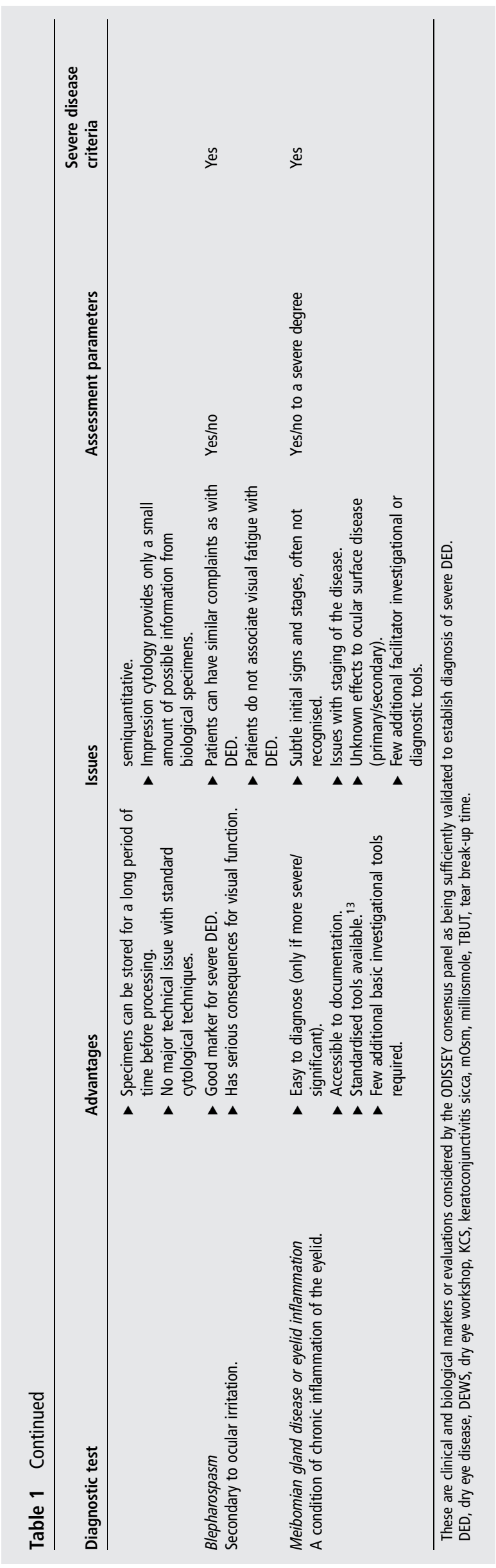

Determinant criteria

Eight of the criteria were classed as determinant to diagnosis of severe DED, and are listed in table 1. The score cut-offs, or grading, which were considered by the panel to indicate severe disease are also presented. Regardless of the scenario (ie, A, B, or $\mathrm{C}$ ), the presence of just one of these clinical criteria in addition to OSDI or corneal fluorescein staining (CSF) severe grading was accepted as diagnosis of severe DED.

\section{Contributory criteria}

Contributory criteria are listed in table 2 and include aberrometry, confocal microscopy, inflammatory markers and refractory to standard disease treatments. Although these criteria have been shown to play a potentially important role in DED diagnosis and severity evaluation (see ${ }^{11}$ and table 2 ), they were categorised as 'contributory' by the panel as their validity is not yet well established, and they are not yet routinely evaluated in the clinical setting. Similarly, there exist no standardised methods for evaluating their outcome.

\section{Other contributory factors}

TBUT was considered by the panel to have a specialised role in the diagnosis and evaluation of DED. TBUT is a routine test for tear instability, and the panel agreed that it is essential for confirming/verifying diagnosis of dry eye in cases of a high symptomatology score with a negative or low CFS score (ie, Scenario C). However, the methodology is far from standardised (see table 2), and the resulting wide variation in test performance can lead to misinterpretation of TBUT findings. ${ }^{8}$ The panel, therefore, added the caveat that TBUT must be regarded as a 'contributory' criterion in patient scenarios where CFS-determined ocular damage is high but symptom severity is low (ie, Scenario A), or if symptom severity is high but ocular damage is borderline (ie, Scenario B).

The hierarchy of determinant and contributory factors for each scenario, as determined by panel consensus is outlined in table 3. The specific evaluation pathway for each scenario is discussed below and shown in figure 2 .

\section{Scenario A: OSDI $<33$ and CFS score $\geq 3$}

If the patient presents significant ocular damage determined by CFS, but symptom severity is relatively mild, the additional presence of one or more of the determinant factors listed in table 3 is sufficient to establish severe DED diagnosis. The panel noted that in this scenario, diminished corneal sensitivity should also be considered as an additional determinant sign. The presence of deeply impaired corneal sensitivity plus a CFS score $\geq 3$ would therefore be sufficient to establish severe DED in this clinical setting.

\section{Scenario $\mathrm{B}$ : $\mathrm{OSDI} \geq 33$ and $\mathrm{CFS}=$ grade 2}

If symptom score is high, but CFS ocular signs do not quite meet the panel-defined level for severe DED, the panel determined that the presence of one of the additional determinant factors listed in table 3 is sufficient to establish severe DED diagnosis. However, the algorithm for Scenario B is distinct from Scenario A in that corneal sensitivity is not considered as a determinant factor in this case. This is because the OSDI score already confirms adequate corneal sensitivity.

\section{Scenario C: $0 S D I \geq 33$ and $C F S \leq 1$}

Scenario C represents major discordance between symptoms and CFS grading, and as such, requires particular attention. The 
Table 2 Summary of contributory DED criteria

\begin{tabular}{|c|c|c|c|c|}
\hline Diagnostic test & Advantages & Issues & Assessment parameters & $\begin{array}{l}\text { Severe } \\
\text { disease } \\
\text { criteria }\end{array}$ \\
\hline $\begin{array}{l}\text { Refractory to standard disease treatments } \\
\text { Disease shows lack of therapeutic response }\end{array}$ & $\begin{array}{l}\text { Apparently a clinical indicator of severity. } \\
\text { Might indicate ocular surface inflammation. } \\
\text { May distinguish between mild and severe cases of } \\
\text { DED. } \\
\text { Might be used as an indication to initiate long term } \\
\text { anti-inflammatory treatment (ie, topical } \\
\text { cyclosporine). }\end{array}$ & $\begin{array}{l}\text { Definition of 'standard treatment' is critical. } \\
\text { Not all the patients receive the same standard } \\
\text { treatment. } \\
\text { Refractoriness could be the consequence of } \\
\text { inappropriate standard treatments. }{ }^{42} \\
\text { Severity staging is needed. } \\
\text { Discordance of symptoms and signs may be a } \\
\text { pitfall. } \\
\text { Long-term anti-inflammatory therapies, topical } \\
\text { and systemic, may induce adverse events. }\end{array}$ & Not established & - \\
\hline $\begin{array}{l}\text { Confocal microscopy } \\
\text { May provide a non-invasive way to visualise high-resolution } \\
\text { histologic-like patterns of the ocular surface structures. }\end{array}$ & $\begin{array}{l}\text { High resolution in vivo tissue examination. } \\
\text { Minimally invasive. } \\
\text { Useful for counting inflammatory cells and } \\
\text { investigating corneal nerves. } \\
\text { Provides overview of the whole ocular surface, } \\
\text { including cornea, conjunctiva and limbus. }\end{array}$ & $\begin{array}{l}\text { Time-consuming. } \\
\text { Expensive device not widely available. } \\
\text { Needs an expert observer for specific } \\
\text { diagnoses. } \\
\text { Lack of scoring systems and quantitative } \\
\text { methods. } \\
\text { (images of narrow areas with limited value). }\end{array}$ & Not established in clinical setting & - \\
\hline $\begin{array}{l}\text { Aberrometry } \\
\text { Objective measurement of the time course of high-order aberrations } \\
\text { may constitute an instrument to evaluate and manage patients } \\
\text { with DED. }\end{array}$ & $\begin{array}{l}\text { Non-invasive system. } \\
\text { Gives rapid information about patient's visual } \\
\text { problems. } \\
\text { Useful for global definition of tear film conditions as } \\
\text { a good indicator of tear film instability. } \\
\text { Easily repeatable, can be used to monitor therapy } \\
\text { efficacy. } \\
\text { - High sensitivity. }\end{array}$ & $\begin{array}{l}\text { Expensive instrument not easily available in all } \\
\text { offices. } \\
\text { Lack of specificity for the disease. } \\
\text { Influenced by environmental conditions, quality } \\
\text { of the last blink. } \\
\text { Influenced by eye drops instillation. } \\
\text { Unable to help characterise the disease. } \\
\text { There is no objective way to extrapolate results } \\
\text { and to predict real visual acuity of the patient. }\end{array}$ & Not well established & - \\
\hline $\begin{array}{l}\text { Inflammatory markers HLA-DR expression } \\
\text { HLA DR class II antigen is an immune marker abnormally expressed } \\
\text { by epithelial cells in inflammatory conditions. }\end{array}$ & $\begin{array}{l}\text { Minimally invasive sample collection of conjunctival } \\
\text { imprints. } \\
\text { Expressed by the most important cell population of } \\
\text { the conjunctiva, that is, epithelial cells. } \\
\text { Large range of values; normal to severe dry eye. } \\
\text { Highly expressed in inflammatory and immune } \\
\text { diseases. } \\
\text { Technique validated in several international } \\
\text { multicentre trials with a central reading centre. }\end{array}$ & $\begin{array}{l}\text { Technique time-consuming; needs appropriate } \\
\text { staff and expensive material } \\
\text { Strict rules for collecting and sending } \\
\text { specimens. } \\
\text { Limited time before sample examination. } \\
\text { - Mainly designed for research and clinical trials. }\end{array}$ & $\begin{array}{l}\text { Used as a biomarker in clinical trials, } \\
\text { not established in clinical setting }\end{array}$ & - \\
\hline $\begin{array}{l}\text { Other inflammatory markers } \\
\text { MMP9, cytokines, proteomics and Luminex assays. }\end{array}$ & $\begin{array}{l}\text { Study disease pathogenesis at the molecular level. } \\
\text { Minimal tear sample volumes needed. } \\
\text { Possible multiple determinations for cytokines and } \\
\text { MMPs. } \\
\text { Precise/objective determination of molecular } \\
\text { quantity. } \\
\text { Easy collection: possible to analyse eluate from } \\
\text { Schirmer's strips, cytology specimens, tear samples. }\end{array}$ & $\begin{array}{l}\text { Not definitely established correlation with } \\
\text { severity of the disease. } \\
\text { Not well defined role in specific dry eye } \\
\text { pathogenic subgroups. } \\
\text { Methods not yet very feasible for diagnostic } \\
\text { purposes }{ }^{49} \\
\text { Labs not available in all clinical centres (useful } \\
\text { only for smaller phase } 2 \text { or phase } 3 \text { trials). }\end{array}$ & Not well established. & - \\
\hline
\end{tabular}




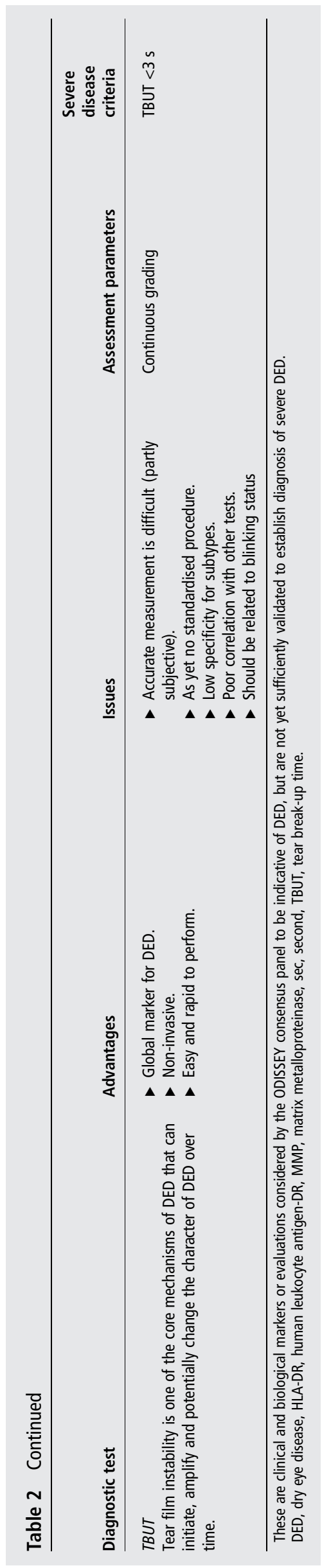

panel recommended that if reported symptoms are severe, but there is no immediate correlation with clinical signs as assessed by CFS grade, the diagnosis of DED should be reconsidered (but not necessarily discarded). Use of the TBUT test in this scenario is, therefore, a prerequisite as a preliminary step (see figure 2) to evaluate tear film instability and confirm the original diagnosis of DED. A more comprehensive understanding of the patient case is also necessary (eg, use of an in-depth patient questionnaire to further determine quality of life, mood evaluation, etc.).

It is of note that filamentary keratitis is not considered as an additional determinant criteria in the case of Scenario C, as objective ocular symptoms determined by CFS have already been confirmed as mild (table 3). Similar to Scenario B, corneal sensitivity testing is not required, as the OSDI score is satisfactory.

\section{CONCLUSIONS}

The ophthalmological field requires a reliable algorithm for patient-tailored evaluation of ocular surface damage, enabling definitive diagnosis of severe DED. ${ }^{7}$ However, reliable assessment of DED severity can be problematic due to several issues, including poorly standardised evaluation methods, noncorrelation between disease severity and clinical/biological disease markers, and individual variability in symptomatology and disease signs. The vicious circle of DED pathogenesis, which can exacerbate the condition and facilitate merging or development of mechanistically distinct DED subtypes can further hinder accurate evaluation. ${ }^{21} 132242$

The ODISSEY scoring algorithm for severe DED diagnosis is a simple, easy-to-use and practical tool, which facilitates assessment of ocular surface damage and evaluation of disease severity. For the majority of DED patients who have a good symptom and sign correlation, OSDI and CFS are adequate to establish DED severity. For patients with symptom and sign dissociation, the evaluation of additional specific criteria are recommended to ascertain disease severity. It is hoped that use of this 'bespoke' diagnostic algorithm for evaluating severe DED will allow for targeted disease monitoring and treatment, and will also improve clinical trial outcome assessment.

Several systems for classifying DED severity already exist. The Triple Classification System bases severity on the continuing presence of symptoms, along with increasing signs of disease. $^{43} 44$ The DEWS approach ranks DED severity on four levels, centred around simultaneous exacerbation of signs and symptoms. ${ }^{5}$ New Japanese DED diagnostic criteria now include symptomatology, and the presence of symptoms and signs is required for a diagnosis of 'definite dry eye', which correlates with more severe disease. ${ }^{1145} 46$ All these classification systems require severe signs and severe symptoms for a diagnosis of severe disease. However, the ODISSEY scoring algorithm provides diagnostic pathways for patients with more complex discordant DED.

There are several limitations to the use of this model. The method of panel-based consensus is by its very nature not necessarily evidence based. The paucity of 'gold-standard' DED biomarkers with well-established criteria also impacts any attempt to standardise DED severity evaluation. Furthermore, the use of specific recommended assessments will heavily depend on local availability, training and cost. There is also an issue of preexisting differences in definitions of dry eye. For example, the Japanese recognise a short break-up time, dry eye condition, characterised by very short TBUT and severe symptoms, but with minimal surface damage. ${ }^{6} 47$ This scenario is very similar to Scenario $\mathrm{C}$ of the algorithm presented in this paper. The 
Table 3 Summary of determinant (ie, validated) and contributory (ie, indicative) diagnostic criteria and grading recommended by the ODISSEY panel to be used to establish severe DED in the case of symptom and sign discordance (ie, scenario $A, B$, or C)

\begin{tabular}{|c|c|c|c|c|}
\hline Criteria type & Evaluations & Scenario A & Scenario B & Scenario C \\
\hline Determinant & Schirmer test: $<3 \mathrm{~mm}$ & $\mathrm{X}$ & $\mathrm{X}$ & $X$ \\
\hline \multirow{8}{*}{ Criteria } & MGD or eyelid inflammation: severe & $\mathrm{X}$ & $\mathrm{X}$ & $\mathrm{X}$ \\
\hline & Conjunctival staining (also conjunctivochalasis/conjunctival folds: severe degree & $\mathrm{X}$ & $X$ & $x$ \\
\hline & $\begin{array}{l}\text { Impaired visual function (photophobia, visual acuity modifications, low contrast sensitivity, or any } \\
\text { combination of the above) }\end{array}$ & $x$ & $x$ & $x$ \\
\hline & Filamentary keratitis & $\mathrm{X}$ & $x$ & $N A^{*}$ \\
\hline & Blepharospasm & $X$ & $\mathrm{X}$ & $\mathrm{X}$ \\
\hline & Hyperosmolarity: $>328 \mathrm{m0sm} / \mathrm{L}$ & $\mathrm{X}$ & $\mathrm{x}$ & $\mathrm{X}$ \\
\hline & Impression cytology: $\geq$ grade 3 (Nelson Scale) & $\mathrm{X}$ & $\mathrm{X}$ & $\mathrm{X}$ \\
\hline & Corneal sensitivity: deeply impaired & $\mathrm{x}$ & $N A t^{2}$ & NAt \\
\hline Contributory & TBUT $<3 \mathrm{~s}$ & $x$ & $\mathrm{X}$ & NA $\ddagger$ \\
\hline \multirow[t]{4}{*}{ Criteria } & Refractory to standard disease treatments & $X$ & $\mathrm{X}$ & $\mathrm{X}$ \\
\hline & Aberrometry & $x$ & $\mathrm{X}$ & $x$ \\
\hline & Confocal microscopy & $\mathrm{X}$ & $\mathrm{X}$ & $x$ \\
\hline & Inflammatory markers: HLA-DR, MMP9, cytokines and proteomics & $X$ & $\mathrm{X}$ & $\mathrm{X}$ \\
\hline
\end{tabular}

Japanese do not consider this condition severe, however, following the DEWS approach and the algorithm presented here, it would satisfy criteria for diagnosis as severe DED.

Nevertheless, by using a hierarchical approach to provide a range of acceptable marker options relevant for each patient it is hoped that, after extensive validation, this algorithm can be broadly applied across a range of clinical and geographical settings.

The next stage is to test the validity of the ODISSEY scoring algorithm in the context of clinical trials. It is hoped implementation of this tool will help to better define trial outcomes and accelerate clinical development of new treatments. Once validated, this algorithm will also aid the ophthalmologist in patient follow-up and treatment optimisation.

Acknowledgements The authors would like to thank Scinopsis Medical Writing for their help with this manuscript.

Collaborators Prof. Michael Lemp.

Contributors The authors are representative members of the European ODISSEY group and a thank you on behalf of the European ODISSEY group to Prof. Michael Lemp (Georgetown University, Washington, USA) for his exceptional contribution.

Funding The ODISSEY European Consensus Group meeting and this manuscript was funded by Santen Pharmaceutical Co., Ltd. Santen has no input into the meeting and content of this article.

Competing interests $C B$ is consultant for, or has received research grants from, Alcon, Allergan, Santen and Thea. PA is consultant for, or has research grant from, Alcon Italia, Allergan, Medivis, Santen, SIFI, Sooft, Thea. MR is consultant for, or has received research grants from, Alcon, Allergan, Bausch \& Lomb, Santen, and TRB Chemedica. ML is consultant to TearLab, TearScience, Merck, Santen.

Provenance and peer review Not commissioned; externally peer reviewed.

Open Access This is an Open Access article distributed in accordance with the Creative Commons Attribution Non Commercial (CC BY-NC 3.0) license, which permits others to distribute, remix, adapt, build upon this work non-commercially, and license their derivative works on different terms, provided the original work is properly cited and the use is non-commercial. See: http://creativecommons.org/ licenses/by-nc/3.0/

\section{REFERENCES}

1 Clegg JP, Guest JF, Lehman A, et al. The annual cost of dry eye syndrome in France, Germany, Italy, Spain, Sweden and the United Kingdom among patients managed by ophthalmologists. Ophthalmic Epidemiol 2006;13:263-74.
2 The epidemiology of dry eye disease: report of the Epidemiology Subcommittee of the International Dry Eye Workshop. Ocul Surf 2007;5:93-107.

3 Sjögren H. Zur Kenntnis dur keratoconjunctivitis sicca (keratitis filiformis bei hypofunktion der Tranendrüsen). Acta Ophthalmol 1933;(11 Suppl 2):1-151.

4 Lemp MA. Report of the National Eye Institute/Industry workshop on Clinical Trials in Dry Eyes. CLAO J 1995;21:221-32.

5 The definition and classification of dry eye disease: report of the Definition and Classification Subcommittee of the International Dry Eye WorkShop. Ocul Surf 2007:5:75-92.

6 Yokoi N, Kinoshita S, Sakai R, et al. A Comparative Study between Short Breakup Time Dry Eye and Other Disorders Giving Rise to a Short Breakup. Invest Ophthalmol Vis Sci 2011;52: E-Abstract 3854.

7 Sullivan DA, Hammitt KM, Schaumberg DA, et al. Report of the TFOS/ARVO Symposium on global treatments for dry eye disease: an unmet need. Ocul Surf 2012;10:108-16.

8 Savini G, Pinita P, Takashi K, et al. The challenge of dry eye diagnosis. Clin Ophthalmol 2008;2:31-55.

9 Sullivan BD, Whitmer D, Nichols KK, et al. An objective approach to dry eye disease severity. Invest Ophthalmol Vis Sci 2010;51:6125-30.

10 Schein OD, Tielsch JM, Munoz B, et al. Relation between signs and symptoms of dry eye in the elderly. Ophthalmology 1997;104:1395-401.

11 Methodologies to diagnose and monitor dry eye disease: report of the Diagnostic Methodology Subcommittee of the International Dry Eye WorkShop. Ocul Surf 2007:5:108-52.

12 Lemp MA, Baudouin C, Amrane M, et al. Poor correlation between dry eye disease (DED) signs and symptoms in a phase III randomized clinical trial [abstract]. Invest Ophthalmol Vis Sci 2011;52:3821.

13 Foulks GN. Challenges and pitfalls in clinical trials of treatments for dry eye. Ocul Surf 2003;1:20-30.

14 Bron AJ. Diagnosis of dry eye. Surv Ophthalmol 2001;45:S221-6.

15 Goto T, Zheng X, Klyce SD, et al. A new method for tear film stability using videokeratography. Am J Ophthalmol 2003;135:607-12.

16 Murube J. Tear osmolarity. Ocul Surf 2006;1:62-73.

17 Tomlinson A, Khanal S, Ramaesh K, et al. Tear film osmolarity: determination of a referent for dry eye diagnosis. Invest Ophthalmol Vis Sci 2006;47:4309-15.

18 Pflugfelder SC, Jones D, Ji Z, et al. Altered cytokine balance in the tear fluid and conjunctiva of patients with Sjögren's syndrome keratoconjunctivitis sicca. Curr Eye Res 1999:19:201-11.

19 Tsubota K, Fujihara T, Saito K, et al. Conjunctival epithelium expression of HLA-DR in dry eye patients. Ophthalmologica 1999;213:16-19.

20 Calonge M, Enríquez-de-Salamanca A, Diebold Y, et al. Dry eye disease as an inflammatory disorder. Ocul Immunol Inflamm 2010;18:244-53.

21 Research in dry eye: report of the Research Subcommittee of the International Dry Eye Workshop. Ocul Surf 2007:5:179-93.

22 Baudouin C. The vicious circle in dry eye syndrome: a mechanistic approach. J Fr Ophtalmol 2007;3:239-46.

23 Baudouin C, Aragona P, Messmer EM, et al. Role of hyperosmolarity in the pathogenesis and management of dry eye disease: proceedings of the OCEAN group meeting. Ocul Surf 2013;11:246-58. 
24 Belmonte C, Acosta MC, Gallar J. Neural basis of sensation in intact and injured corneas. Exp Eye Res 2004;78:513-25.

25 Begley CG, Chalmers RL, Abetz L, et al. The relationship between habitual patient-reported symptoms and clinical signs among patients with dry eye of varying severity. Invest Ophthalmol Vis Sci 2003:44:4753-61.

26 Rosenthal P, Borsook D. The corneal pain system. Part I: the missing piece of the dry eye puzzle. Ocul Surf 2012;10:2-14.

27 Nichols KK, Nichols JJ, Mitchell GL. The lack of association between signs and symptoms in patients with dry eye disease. Cornea 2004a;23:762-70.

28 Viso E, Rodríguez-Ares MT, Abelenda D, et al. Prevalence of asymptomatic and symptomatic meibomian gland dysfunction in the general population of Spain. Invest Ophthalmol Vis Sci 2012:53:2601-6.

29 Lemp AM. Advances in understanding and managing dry eye disease. Am J Ophthalmol 2008;146:350-6.

30 Adatia FA, Michaeli-Cohen A, Naor J, et al. Correlation between corneal sensitivity, subjective dry eye symptoms and corneal staining in Sjögren's syndrome. Can J Ophthalmol 2004;39:767-71.

31 Bourcier T, Acosta MC, Borderie V, et al. Decreased corneal sensitivity in patients with dry eye. Invest Ophthalmol Vis Sci 2005;46:2341-5.

32 M'garrech M, Rousseau A, Kaswin G, et al. Impairment of Lacrimal secretion in the unaffected fellow eye of patients with recurrent unilateral Herpetic keratitis. Ophthalmology 2013;120:1959-67.

33 Behrens A, Doyle JJ, Stern L, et al. Dysfunctional tear syndrome study group. Dysfunctional tear syndrome: a Delphi approach to treatment recommendations. Cornea 2006:25:900-7.

34 Varma R, Richman EA, Ferris FL III, et al. Use of patient-reported outcomes in medical product development: a report from the 2009 NEI/FDA Clinical Trial Endpoints Symposium. Invest Ophthalmol Vis Sci 2010;51:6095-103.

35 Begley C, Caffery B, Chalmers R, et al. Use of the Dry Eye Questionnaire to measure symptoms of ocular irritation in patients with aqueous tear deficiency. Cornea 2002;21:664-70.

36 Abetz L, Rajagopalan K, Mertzanis P, et al. Impact of Dry Eye on Everyday Life (IDEEL) Study Group. Development and validation of the impact of dry eye on everyday life (IDEEL) questionnaire, a patient-reported outcomes (PRO) measure for the assessment of the burden of dry eye on patients. Health Qual Life Outcomes 2011;9:111.

37 McMonnies C, Ho A, Wakefield D. Optimum dry eye classification using questionnaire responses. Adv Exp Med Biol 1998;438:835-8.

38 Nichols KK, Nichols JJ, Mitchell GL. The reliability and validity of McMonnies Dry Eye Index. Cornea 2004b;23:365-71.

39 Gothwal VK, Pesudovs K, Wright TA, et al. McMonnies questionnaire: enhancing screening for dry eye syndromes with Rasch analysis. Invest Ophthalmol Vis Sci 2010;51:1401-7.

40 Miller KL, Walt JG, Mink DR, et al. Minimal clinically important difference for the ocular surface disease index. Arch Ophthalmol 2010;128:94-101.

41 Savini $G$, Barboni $P$, Zanini $M$. The incidence and risk factors for developing dry eye after myopic LASIK. Am J Ophthalmol 2006;142:355-6.

42 Aragona $\mathrm{P}$, Rolando M. Towards a dynamic customised therapy for ocular surface dysfunctions. Br J Ophthalmol 2013;97:955-60.

43 Murube J, Benitez del Castillo JM, Chenghou L, et al. The Madrid triple classification system. Arch Soc Esp Oftalmol 2003;78:587-93.

44 Murube J, Nemeth J, Hoh $\mathrm{H}$, et al. The triple classification of dry eye for practical clinical use. Eur J Ophthalmol 2005;15:660-7.

45 Uchino $Y$, Uchino $M$, Dogru $M$, et al. Changes in dry eye diagnostic status following implementation of revised Japanese dry eye diagnostic criteria. Jpn J Ophthalmol 2012;56:8-13.

46 Miyawak IS, Nishiyama S. Classification criteria for Sjogrens syndromesensitivity and specificity of criteria of the Japanese Ministry of Health and Welfare (1977) and criteria of European community (1993). Nippon Rinsho 1995; $53: 2371-5$

47 Yamamoto Y, Yokoi N, Higashihara $\mathrm{H}$, et al. Clinical characteristics of short tear film breakup time (BUT) -type dry eye. Nihon Ganka Gakkai Zasshi 2012:116:1137-43.

48 Singh R, Joseph A, Umapathy $T$, et al. Impression cytology of the ocular surface. Br J Ophthalmol 2005;89:1655-9.

49 Sambursky R, Davitt WF III, Latkany R, et al. Sensitivity and specificity of a point-of-care matrix metalloproteinase 9 immunoassay for diagnosing inflammation related to dry eye. JAMA Ophthalmol 2013;131:24-8. 